\title{
Evaluation and Analysis of Hospital Disaster Preparedness in Jeddah
}

\author{
Nidaa A. Bajow ${ }^{1}$, Shahnaz M. Alkhalil ${ }^{2}$ \\ ${ }^{1}$ Department of Disaster Medicine Unit, King Fahd Security Collage, Riyadh, Saudi Arabia \\ ${ }^{2}$ Department of Mechanical Engineering, Al-Zaytoonah University of Jordan, Amman, Jordan \\ Email: dr.nidaaa@gmail.com, eng.shahnaz@gmail.com
}

Received 12 September 2014; revised 27 October 2014; accepted 10 November 2014

Copyright (C) 2014 by authors and Scientific Research Publishing Inc.

This work is licensed under the Creative Commons Attribution International License (CC BY). http://creativecommons.org/licenses/by/4.0/

cc) (i) Open Access

\begin{abstract}
Introduction: Disaster damage to health systems is a human and health tragedy, results in huge economic losses, deals devastating blows to development goals, and shakes social confidence. Hospital disaster preparedness presents complex clinical operation. It is difficult philosophical challenge. It is difficult to determine how much time, money, and effort should be spent in preparing for an event that may not occur. Health facilities whether hospitals or rural health clinics, should be a source of strength during emergencies and disasters. They should be ready to save lives and to continue providing essential emergencies and disasters. Jeddah has relatively a level of disaster risk which is attributable to its geographical location, climate variability, topography, etc. This study investigates the hospital disaster preparedness (HDP) in Jeddah. Methods: Questionnaire was designed according to five Likert scales. It was divided into eight fields of $\mathbf{3 3}$ indicators: structure, architectural and furnishings, lifeline facilities' safety, hospital location, utilities maintenance, surge capacity, emergency and disaster plan, and control of communication and coordination. Sample of six hospitals participated in the study and rated to the extent of disaster preparedness for each hospital disaster preparedness indicators. Two hazard tools were used to find out the hazards for each hospital. An assessment tool was designed to monitor progress and effectiveness of the hospitals' improvement. Weakness was found in HDP level in the surveyed hospitals. Disaster mitigation needs more action including: risk assessment, structural and nonstructural prevention, and preparedness for contingency planning and warning and evacuation. Conclusion: The finding shows that hospitals included in this study have tools and indicators in hospital preparedness but with lack of training and management during disaster. So the research shed light on hospital disaster preparedness. Considering the importance of preparedness in disaster, it is necessary for hospitals to understand that most of hospital disaster preparedness is built in the hospital system.
\end{abstract}

\section{Keywords}

Hospital Disaster Preparedness Indicators (HDPI), Hospital Disaster Preparedness (HDP), Hazard 


\section{Introduction}

Lately Saudi Arabia has become a typical region for hazard. Floods and other hazards are observed in Jeddah, a Saudi city on the Red Sea to the west, which have lately affected many people and damaged the infrastructure. The lack of HDP exacerbated the problem. The purpose of this study is to investigate the HDP and imply an assessment tool of hazard.

Making hospitals and health facilities safe from disasters is an economic requirement. It is also a social, moral and ethical necessity of life, and thus the price we pay for the failure of our hospitals due to disasters is too high. In comparison to the cost of making them safe from disasters that is so tiny [1].

Several hospitals in Saudi Arabia have become familiar with hospital disaster preparedness but only in written forms to meet Joint Commission on Accreditation of Healthcare Organizations standard. Rare of these hospitals have exercised these documents [2].

Jeddah floods in 2009 put all hospitals in critical situation and many questions were raised in authorities' minds such as: have the hospitals in Jeddah area been prepared really to meet any hazards which they are faced with? Another question that may arise is Do the essential hospitals - that belong to the Minster of health-respond to disaster-and do they during emergency make their own plan according to hazards map and do they educate their staff and train them according to proper standards?

For an example, during 2009 flood many hospital services suffered paralysis due to the fact that all computer systems and software analysis with the availability of all air conditioning units were much disrupted, and the majority of devices in basement in some hospitals were disrupted and soaked in water [3]. There is much said and written about hospitals preparedness in case of emergencies, however there is no accepted gold rule or standard that may be applied to all hospitals_-for there are many levels of hospitals all over the world—and for all types of disasters. Different levels of hospitals have different capacities, resources and capabilities: thus it is difficult to find a standard method of evaluating readiness that can be applied to all types of hospitals. Also, standards, resources, hazards and needs differ internationally. Many various different factors can be found in most of hospital preparedness indicators such as: buildings, patients, hospital beds, medical and support staff, equipment and facilities, basic lifelines and services [4].

In this research the assessment process based on the field study conducted that was done during hospitals visits and survey. Data was collected though the questionnaire; the questionnaire was designed to direct respondents to follow-on items, only if the overall indicator was used within the hospital; Responses of participants were collected, coded, and entered into a Microsoft Excel sheet. The data was then coded according to categorical Likert scale responses. Then detailed statistical analysis was carried out. Frequency distributions and descriptive statistics were used to summarize high-level analysis of responses.

The hospital disaster preparedness indicators (HDPI) that are used in this research structures are: architectural and furnishing, safety of lifeline facilities, hospital location and areas, maintenance of utilities, surge capacity, emergency and disaster plan, control of communication and coordination.

\section{Hospital Disaster Preparedness Indicators}

By reviewing other published work regarding HDP many studies led attention to shortcomings in HP with respect to the acute medical response to a disasters [5]-[10]. Deficient hospital disaster planning and preparedness is more pronounced in developing countries as compared to developed countries [11]. Majority who are injured and killed by natural disasters reside in developing countries [12]. Thus, the impact of poor disaster planning is more pronounced for developing countries. Prior studies have shown that the socioeconomic level of a community influences the vulnerability of its inhabitants and their medical requirements in the event of a disaster [11].

There is much written about preparedness of hospitals, however there is no accepted gold standard that can be applied to all hospitals—-for there are different levels of hospitals, in different parts of the world—and for all 
disasters. Table 1 shows HDPI that are used in this research followed by a brief description for each item.

\subsection{Structural Indicators of Safe Hospital}

Structural elements are essential in health facilities that determine the overall safety of the building, such as the foundations, the columns, the beams, the slabs, the load-bearing walls, the braces, and the trusses [4].

\section{1-Hospital Structure}

The structural vulnerability of the hospital buildings should be cross checked with hazard maps before it is actually built due to the fact that hospital buildings are not at the edge of a slope or near the foot of a mountain vulnerable to landslide. The buildings are not near creeks, rivers or bodies of water that could erode its foundation [4].

\section{Table 1. HDPI that are used in this research.}

\begin{tabular}{|c|c|c|}
\hline No. & \multicolumn{2}{|c|}{ Hospital disaster preparedness indicators (HDPI) } \\
\hline 1 & Structure & 1.1. Hospital structure \\
\hline \multirow{4}{*}{2} & \multirow{4}{*}{ Architectural and furnishings } & 2.1. Safety of the roofing and ceilings \\
\hline & & 2.2. Safety of doors and windows \\
\hline & & 2.3. Safety of walls, divisions, partitions \\
\hline & & 2.4. Safety of floor coverings \\
\hline \multirow{6}{*}{3} & \multirow{6}{*}{ Safety of Lifeline Facilities } & 3.1. Electrical tools System \\
\hline & & 3.2. Communication tools System \\
\hline & & 3.3. Water Supply tools System \\
\hline & & 3.4. Medical Gas tools System \\
\hline & & 3.5. Fire Suppression tools System \\
\hline & & 3.6. Emergency Exit System \\
\hline \multirow{3}{*}{4} & \multirow{3}{*}{ Hospital location and areas } & 3.7. Heating, Ventilation and Air conditioning Systems in Critical Areas \\
\hline & & 4.1. Site and Accessibility \\
\hline & & 4.2. Zoning of hospital units \\
\hline \multirow{4}{*}{5} & \multirow{4}{*}{ Maintenance of Utilities } & 5.1. Water supply system \\
\hline & & 5.2. Electrical system \\
\hline & & 5.3. Medical Gases Distribution System \\
\hline & & 5.4. Waste management system (solid and water) \\
\hline \multirow{3}{*}{6} & \multirow{3}{*}{ Surge capacity } & 6.1. Staff \\
\hline & & 6.2. Stuff \\
\hline & & 6.3. Structure \\
\hline \multirow{8}{*}{7} & \multirow{8}{*}{ Emergency and Disaster plan } & 7.1. Hazard map \\
\hline & & 7.2. Information \\
\hline & & 7.3. Committee \\
\hline & & 7.4. Preparedness \\
\hline & & 7.5. The Hospital Emergency Incident Command System \\
\hline & & 7.6. Stage of activation \\
\hline & & 7.7. Emergency operations center \\
\hline & & 7.8. Surveillance system \\
\hline \multirow{4}{*}{8} & \multirow{4}{*}{$\begin{array}{l}\text { Control of communication } \\
\text { and coordination }\end{array}$} & 8.1. Transportation and Communication \\
\hline & & 8.2. Cooperative arrangement with local emergency plan \\
\hline & & 8.3. Referral procedure \\
\hline & & 8.4. Health facility networking \\
\hline
\end{tabular}




\subsection{Non-Structural Indicators of Safe Hospitals}

All other elements without forming part of the resistance systems, enable the hospitals to operate. Such as: architectural elements, equipment, contents and services or lifelines are called the non-structural elements [4].

\section{2-Architectural and Furnishings}

It includes components such as windows, ceilings, partition walls and lighting systems. It also consists of the equipment and furnishings which in turn includes the following: mechanical equipment, medicine containers, medical and laboratory equipment, office furnishings, etc. [13].

-Safety of the roofing and ceilings: There are several types of roofing materials. They must be easy to weld, rivet, and fastener securely. For example ceiling made of concrete must be leaks and cracks free [13].

-Safety of doors and windows: Wind and fire resistant doors must be used. Power-operated doors must be manually operated in case of power failure to allow ease of exit travel. Sun and wind protection devices must be available in windows. Safety of the patient is important so windows must have secure devices [13].

Safety of walls, divisions, partitions: Fire resistant exterior walls and room partitions should be used. Any element like hanging lights must be securely fastened on walls. All electrical cables and wires should also be properly fastened and fixed [13].

-Safety of floor coverings: Non-slippery covering floor materials [4], easy to clean must be used in all hospital areas.

\section{3-Safety of Lifeline Facilities}

In any health facility electric power, water and sanitation and waste treatment and disposal are important lifeline for continuous operations. So special procedures and protocols during disaster must be prepared [13].

-Electrical tools System: The health facility must have an alternative power source in case of power failure like generators with heavy duty power that can meet extra demand. This generator must be in a safe and secure place with proper backup for intensive care and operating room [13].

-Communication tools System: The tools and devices that are used for communication must be fixed well and safely secured. Any outside communication tools must be fixed under the ground [13].

-Water Supply tools System: The hospital demand of water for three days must be available in case of disaster by secure water tank. This water storage must be in a secure and safe place [13].

-Medical Gas tools System: A well ventilated place should be available for medical gas storage. Hence, medical gases must be kept in a secure and safe location [13].

-Fire Suppression tools System: Accredited fire agency must monitor the fire alarm system all times. Immediate response to fire is important by the use of a well fire alarm system. Proper guidelines regarding placement of fire detectors and firefighting equipment should be done in coordination with the local fire department [13].

-Emergency Exit System: Well Illuminated exit signs must be used in special coloring, with a reliable source. Also lighting source is assessed by public utility electric service [13].

-Heating Ventilation and Air conditioning Systems in Critical Areas: These must be fixed well and secured. For example adequate bracing for ducts can be done to ensure safety [13].

\subsection{Functional Indicators of Safe Hospitals}

It is very important that hospitals and health facilities during emergency or disaster are functioning well. Therefore it is necessary to ensure that health services will continue to be provided when they are most needed [13]. The following groups are functional indicators.

\subsubsection{Hospital Location and Areas}

The location of the health facility is vital. It must be away from hazard, dust, noise and fire. Therefore it must be easy to reach from all zones [4].

Site and Accessibility: The hospital or health facility location should be near proper roads and with enough ways of transportation. It must be easy to reach and near educational, religious and commercial centers [13].

Zoning of hospital units: A well distribution of departments within the hospital or health facility will make accessibility to them be easily and safely reached [13]. 


\subsubsection{Maintenance of Utilities}

It is vital in the daily operations of hospitals and health facilities to have adequate water supply, electricity and medical gases. Therefore, maintenance schedule must be available to them [13].

Water supply system: An alternative water source must be available such as a safe water tank. This source of water must be clean and secure [13]. In case of emergency the water source may be damaged, so the alternative source must be ready to use and quickly respond and save time [14].

Electrical System: Electrical supply in hospital must be clear, well organized and safe. Hence, in case of disaster an alternative power supply must be available and work properly [13].

Medical Gases Distribution System: A regularly inspection plan for medical gas containers and pipes should be done. Leak alarm system and safety valves must be used and maintained [13].

Waste management system (solid and water): It is very important to have a proper system to get rid of solid waste system especially in disaster case because extra waste caused by the disaster itself will be available. If this waste stayed it will affect the public health [15]. Hence having an effective wastewater system is vital of any community. Since wastewater system may be affected by hazards and disasters [16].

\subsubsection{Surge Capacity}

Surge capacity is the capability of a hospital to expand its resources to meet a large casualty load without requiring outside help, this is also a function of both space equipment and staff [17].

The most important components are:

Staff: It refers to doctors, nurses, mental health staff, emergency medical techniciansand public health professionals. Hospitals have specific benchmarks for surge capacity staffing and states should create a response system that allows for this [18]. Health professionals are trained via methods of competency based education, in the recognition, treatment and referral of patients exhibiting behavioral health consequences related to any type of public health emergencies [19].

Stuff: This consists of equipment, supplies and medications that should be available on hand for use in major emergencies to keep facilities in constant and effective operation and support proper patient care, including specialized items for specific threats Stockpiles to help provide medical and non-medical supplies during an emergency [20]. We will never have all the required resources to be totally prepared for every disaster, but with appropriate partnerships incident management systems and a tiered response framework we can be to some degree prepared to respond to any arising challenge [21].

Structures: In case of emergency, hospitals must have enough places to convert to patients locations and can increase bed capacity [22]. There must be emergency plans in the hospital to supply extra location, food and staff [20]. Dead bodies' location must be far away from the entrance of the hospital and an alternative morgue place must be available to face extra demand in disaster [23].

\subsubsection{Emergency and Disaster Plan}

Hospital Emergency Preparedness Response and Recovery Plan must be prepared and well tested and exercised in the hospital [4].

Hazard map: The Hazard Vulnerability Analysis (HVA) is an important leader for the facility to concentrate on risks that are most likely happened with the highest threat [17]. Certain plans for dealing with highest 3 to 5 hazards that have been identified and must practice them [24].

Information: Public information; as a recommendation the public information center should be coordinated by a social worker and should be staffed by hospital personnel or volunteers. The hospital's disaster plan should also be provided for the continued functioning of the public information center during disaster/emergency situations Public education should ideally become part of the hospital's disaster plan [22]. Update list for Staff; updated list of addresses and telephone numbers of all staff involved in the emergency preparedness plan should be done on frequent basis and periodically, for example say every 3 months [25]. Medical records; a question should be asked; if patient medical records and billing records were destroyed, is there then some type of backup system for them?

Another question that arises is: Where is the information stored and can it be easily accessed? You may want to consider keeping a backup tape or disk off-site. Paper records; to help protect paper records, you may want to look into fireproof cabinets. Even though this may be expensive, they may help in preserving much needed records [26]. 
Committee: Each hospital should have a disaster committee from multi-disciplinary. Their task is to make a disaster procedure, and to also organize exercise, and to function as troubleshooters when the hazard/disaster becomes real, in addition to co-ordinate with external parties concerned and to manage inventory risks [25].

\section{Preparedness:}

$\sim$ External and internal disaster preparedness; The hospital should always be prepared with written disaster plan that responds to external disasters to help in providing assistance to victims, the hospital is also vulnerable to disasters directly occurring within its walls; so preparation must be made in response to internal disasters, the most common of all is fire [22].

$\sim$ Strengthen essential hospital services; intensive care resources must function well and in a high quality in case of mass casualty incident (MCI) despite number of injuries [27].

$\sim$ Thus, the hazard plan must have certain actions that will to be taken before, during, and after a disaster in the hospital's emergency room, intensive care unit, sterilization unit and operating theater [28].

$\sim$ Education and training; education and training are both important and essential for disaster, and also for disaster services. Good planning and equipment may be of little or no use if the staff has not received appropriate instruction in the function of organization or use of the equipment [15].

$\sim$ Emergency Exercises; the hospital emergency response plan is a guideline of practices that must be done, developed and exercised during disaster event [22]. It is a pre-requisite for applying emergency practices. Therefore nothing to be exercised without this plan [29]. Six known types of exercises are available; 1) orientation; 2) tabletop; 3) game; 4) drill; 5) functional; and 6) Full-Scale Exercises (FSE) [29]. JCAHO requires drills and exercises twice yearly both internal and external [17].

$\sim$ Hospital evacuation plan; a proper plan that explain clearly how to evacuate people and things inside the hospital must be available and practiced regularly [30].

$\sim$ Contingency plans for medical treatment in disasters; Emergency and disaster plan should include contingency plan for special hazards that hospitals are subject to such as: floods, fires and explosion, chemical accidents or exposure to ionizing radiation, pathogens with epidemic potential, psycho-social treatment for patients, families, and health workers [28].

Community Involvement; Community disaster plan must be properly prepared. A special attention must be taken in developing countries due to bad communication and transportation. Patients are difficult to reach hospital in normal cases. Thus the difficulty to arrive health facilities increases in case of disaster. So more effort should be done to exercise such people in these difficult areas [22].

The Hospital Emergency Incident Command System (HEICS): HEICS is a management structure to identify responsibilities, reporting connections, and a common designation to help combine hospitals with other emergency responders [31]. Job descriptions assigned for each functional position within the HEICS must be printed in the job action sheets. The job action sheets must identify the responsible person, clarify the actions that needed to be done and assign reporting to whom [32].

Stage of activation: in case of disaster in the hospital; emergency notification then activation of the chain of command must be both known and performed. After this the operational phase is performed by actual dealing with the mass casualties according to the disaster emergency plan. Then phase of deactivation is declared when hospital command is satisfied that flow of victims is not exceeding the hospital utilities [33].

Emergency Operations Centre (command center): a pre-determined location should be chosen for the Emergency Operations Centre (EOC), the functions of the EOC include [22]; Activation of the plan by the designated persons; Control and coordination of hospital activities; Provision of additional resources; Liaison with the overall emergency control center and Control of field medical services [22].

Surveillance system: both knowledge and the use of epidemiological tools should exist, including routine surveillance systems and disease-reporting procedures. Computer-based surveillance systems should be created to collect and analyze the morbidity, mortality and other epidemiological data for early detection of bioterrorism-related diseases.

This means early and quick detection of typical deaths or syndromes and early and quick detection of the increase of typical deaths or syndromes above the expected levels [34].

\subsubsection{Control of Communication and Coordination}

Transportation and communication; communication is vital to the success of all coordination efforts. Planning for disaster situations should also entail pooling of available resources for patient transportation aside from 
those already in existence. Identifying the availability and capabilities of ambulances is important in maximizing their use during emergencies [22].

Cooperative arrangement with local emergency plan; because hospitals do not function in isolation during a disaster, it is essential for emergency medical services (EMS) and hospital disaster plans to be integrated into the community disaster plan [25].

Referral procedure; hospitals needs special Mechanism during disaster to prepare a census of admitted patients and those referred to other hospitals (forms and procedure to receiving victims with different severity that arrive to hospital by themselves or through ambulance) [28].

Hospital facility networking; the connection between different health care facilities of a certain geographical zone must be available to know the resources. Hence, authorities must have the information about the available health resources in their zone. Information, materials, manpower and training must be networked in the health care facilities [33].

\section{Methods}

Hospitals all over are trying to stay disaster prepared for a long-term period. Most hospitals have a major opportunity to reduce loses through HDPI. HDPI allows the implementation of many tools and techniques that help in solving various problems through the elimination of source of mess in various hospital areas.

Implementation of HDPI in hospital areas provides a potential solution to improve the competitiveness of preparedness; therefore the development of an assessment tool can effectively guide the implementation. The need for such an assessment tool arises due to the need to improve hospital's efficiency. The implementation of the right HDPI at the right time on the right impact area of hospital relies on extensive knowledge and experiences.

The main purpose out of this paper is to investigate the HDPI listed in Table 1 that enables the Jeddah hospitals to be successfully well prepared, and afterwards to develop an assessment tool to review the hospital disaster preparedness (HDP) indicators and the guiding tools to identify the difficulties and opportunities, that provides an effective way to guide and evaluate the preparedness process. The paper aims also to evaluate the level of awareness HDP.

\section{Settings}

This study was conducted in Jeddah in Saudi Arabia, from June 18, 2010 through June, 2011. Random sampling of all hospitals was not possible due to limited access on the basis of permission and authority. Therefore, the selection of hospitals represents a convenience sample; i.e. services area of Health Affairs in Jeddah divided into two categories; essential hospitals and supporting hospitals. So all essential hospital and supporting hospital in Jeddah were included in the study.

Questionnaires were personally distributed; to allow the evaluation of hospital disaster preparedness awareness, implementation status, and the need for developing assessment tool for hospital disaster preparedness in the hospital. To acquire the required information the questionnaire was addressed to the hospitals in order to obtain primary data for this study.

The sample size in this research consisted of all essential and some of the supporting hospitals in Jeddah city. Starting with 8 hospitals, but 2 hospitals from the supporting refused to conduct a field study. So ending up with a sample size of a total of 6 hospitals (hospital and employee as one entity). Hospitals number of beds respectively is (132, 687, 445, 57, 819 and 124).

A five-point Likert scale (Poor, Fair, Good, Very good, and Excellent) was used. The questionnaire was designed for direct respondents to follow-on items, only if the overall indicator were used within the hospital. The structure chosen for the survey items both minimized the amount of time to complete the survey, and also provided the respondent with additional details on a particular indicator through the follow-on items.

Because the follow-on items referenced more specific aspects of hospital disaster preparedness in question, this reduced the likelihood that the respondent would not clearly understand the overall indicator. The structure also provided means for determining the indicators being implemented, as well as the details of how a particular hospital was implementing the indicator. For each item, respondents were asked to evaluate how often specific hospital disaster preparedness were used within their organization. 


\section{The Developed HDP Assessment Tool}

The developed assessment tool reviews the HDPIs and the guiding tools to identify the difficulties and opportunities. The HDP assessment tool is used in conjunction with corporate goals in order to define the gaps in performance and help point out areas of opportunity for "Breakthrough Improvement” in all the indicators mentioned in Table 1, also to monitor progress and effectiveness of the process improvement effort in addition to help in providing a sense of where the hospital is located today on its hospital disaster preparedness journey.

It is based on hospital disaster preparedness indicators. Since this assessment is based on an Excel spreadsheet the navigation through it is through the tabs shown in Figure 1 that include: Introduction-1, 2, 3, 4, 5, 6, 7, 8 and Assessment Score card. Begin by clicking "Introduction” Tab, followed by the " 1 ” Tab, entering a score of 1 to 5; continue for the $8 \mathrm{HDPI}$. Once the 8 scores are entered, a composite score is then automatically calculated, then a Spider Graph for quick review as shown in Figure 2.

\section{The Proposed HDPI Hypotheses}

The hypotheses proposed are explained in Table 2.

\section{Hypotheses Tests and Results Verification}

\subsection{Is There Any Significance Difference in Structure Level among the Hospitals?}

$\mathbf{H o}_{1}$ : No significance difference in Structure level among the hospitals.

$\mathbf{H 1}_{1}$ : There is significance difference in Structure level among the hospitals.

Below are the Minitab results regarding each hypothesis.

Minitab results of $\mathrm{H1}_{1}$ :

\begin{tabular}{|c|c|c|c|c|c|}
\hline \multicolumn{6}{|c|}{ Regression Analysis: 1. Structure-1.1 Hospital_1 versus HOSPITAL NO. } \\
\hline \multicolumn{6}{|c|}{$\begin{array}{l}\text { The regression equation is } \\
\text { 1. Structure-1.1 Hospital_1 }=2.63+0.214 \text { HOSPITAL NO. }\end{array}$} \\
\hline Predictor & Coef & SE Coef & $\mathrm{T}$ & \multicolumn{2}{|r|}{$p$} \\
\hline Constant & 2.6333 & 0.6689 & 3.94 & \multicolumn{2}{|r|}{0.017} \\
\hline HOSPITAL NO. & 0.2143 & 0.1717 & 1.25 & \multicolumn{2}{|r|}{0.280} \\
\hline \multicolumn{2}{|c|}{$S=0.718464$} & & $\mathrm{Sq}=28$. & & $\mathrm{R}-\mathrm{Sq}(\operatorname{adj})=10.0 \%$ \\
\hline \multicolumn{6}{|c|}{ Analysis of Variance } \\
\hline Source & DF & SS & MS & $\mathrm{F}$ & $\mathrm{P}$ \\
\hline Regression & 1 & 0.8036 & 0.8036 & 1.56 & 0.280 \\
\hline Residual Error & 4 & 2.0648 & 0.5162 & & \\
\hline Total & 5 & 2.8683 & & & \\
\hline \multicolumn{6}{|c|}{ Inverse Cumulative Distribution Function } \\
\hline \multicolumn{6}{|c|}{ Student's t distribution with 5 DF } \\
\hline$p(\mathrm{X}<$ & & $\mathrm{x}$ & & & \\
\hline 0.9 & & 2.01505 & & & \\
\hline
\end{tabular}

\section{Interpreting the results:}

$$
\begin{aligned}
& \alpha=0.05 \\
& t_{0}=3.94 \\
& t_{\alpha / 2.5}=2.015 \\
& t_{0}>t_{\alpha / 2.5}
\end{aligned}
$$

Reject $\mathrm{H}_{0}$ if $\mathrm{t}_{0}>\mathrm{t}_{\alpha / 2, \mathrm{n}-2}$ and since $3.94>2.015$. Also $p$-value $=0.017<\alpha=0.05$.

So $\mathbf{H}_{\mathbf{0 1}}$ is rejected. There is significance difference in Structure level among the hospital so far their effect on hospital disaster preparedness is concerned. 


\section{Assessment tool for hospital disaster preparedness}

The hospital disaster preparedness (HDP) Assessment tool should be used to monitor progress and effectiveness of the process improvement effort. The current status can be charted along with the target condition goals.

Indicate the hospital disaster preparedness of each of the following indicators in your hospital, below is the rating scale:

(1) Poor; (2) Fair; (3) Good; (4) Very Good; (5) Excellent

\begin{tabular}{|c|l|}
\hline No. & Hospital disaster preparedness indicators \\
\hline 1 & Structure \\
\hline 2 & Architectural and furnishings \\
\hline 3 & Safety of Lifeline Facilities \\
\hline 4 & Hospital location and areas \\
\hline 5 & Maintenance of Utilities \\
\hline 6 & Surge capacity \\
\hline 7 & Emergency and Disaster plan \\
\hline 8 & Control of communication and coordination \\
\hline
\end{tabular}

Figure 1. The developed HDP assessment tool.

Hospital disaster preparedness progress for Example Hospital

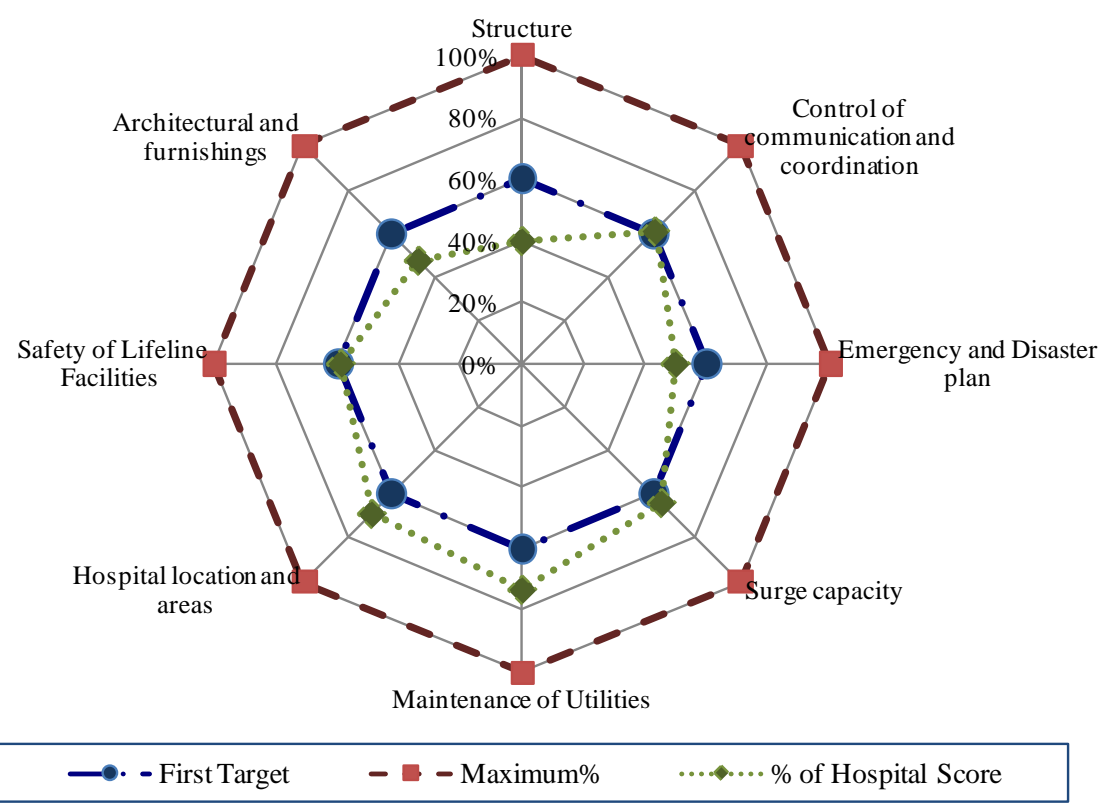

Figure 2. Spider graph of the developed assessment tool.

\subsection{Is There Any Significant Difference in Architectural and Furnishings Level among the Hospitals?}

$\mathbf{H o}_{2}$ : No significance difference in Architectural and furnishings level among the hospitals.

$\mathbf{H 1}_{2}$ : There is significance difference in Architectural and furnishings level among the hospitals. 
Table 2. Summary of proposed hypotheses for HDPI.

\begin{tabular}{ll}
\hline & \multicolumn{1}{c}{ Hypotheses } \\
$\mathrm{H} 1_{1}$ & There is significance difference in Structure level among the hospitals. \\
$\mathrm{H} 1_{2}$ & There is significance difference in Architectural and furnishings level among the hospitals. \\
$\mathrm{H} 1_{3}$ & There is significance difference in Safety of Lifeline Facilities level among the hospitals. \\
$\mathrm{H} 1_{4}$ & There is significance difference in Hospital location and areas level among the hospitals. \\
$\mathrm{H} 1_{5}$ & There is significance difference in Maintenance of Utilities level among the hospitals. \\
$\mathrm{H} 1_{6}$ & There is significance difference in Surge capacity level among the hospitals. \\
$\mathrm{H} 1_{7}$ & There is significance difference in Emergency and Disaster plan level among the hospitals. \\
$\mathrm{H} 1_{8}$ & There is significance difference in Control of communication and coordination level among the hospitals.
\end{tabular}

\section{Minitab results of $\mathrm{H1}_{2}$ :}

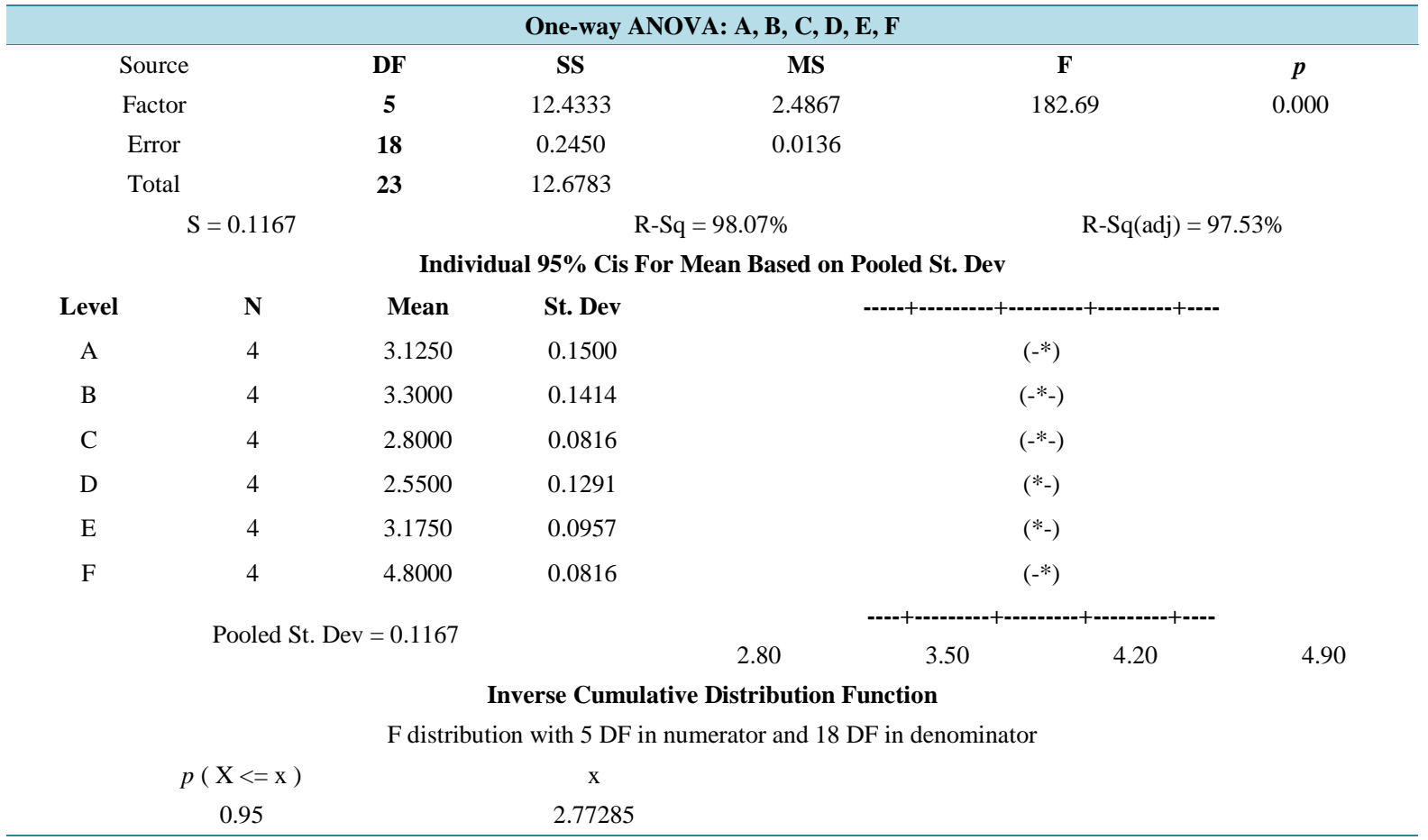

Interpreting the results:

$$
\begin{aligned}
& \alpha=0.05 \\
& f_{0}=182.69 \\
& f_{0.05,5.18}=2.77 \\
& f_{0}>f_{\alpha, 5.18}
\end{aligned}
$$

So $\mathbf{H}_{\mathbf{0} 2}$ is rejected. Also $p$-value $=0.0<\alpha=0.05$. There is significance difference in Architectural and furnishings level among the hospitals so far their effect on hospital disaster preparedness is concerned.

\subsection{Is There Any Significant Difference in Safety of Lifeline Facilities Level among the Hospitals?}

$\mathbf{H}_{\mathbf{0} 3}$ : No significance difference in Safety of Lifeline Facilities level among the hospitals.

$\mathbf{H 1}_{3}$ : There is significance difference in Safety of Lifeline Facilities level among the hospitals.

Minitab results of $\mathrm{H1}_{3}$ : 


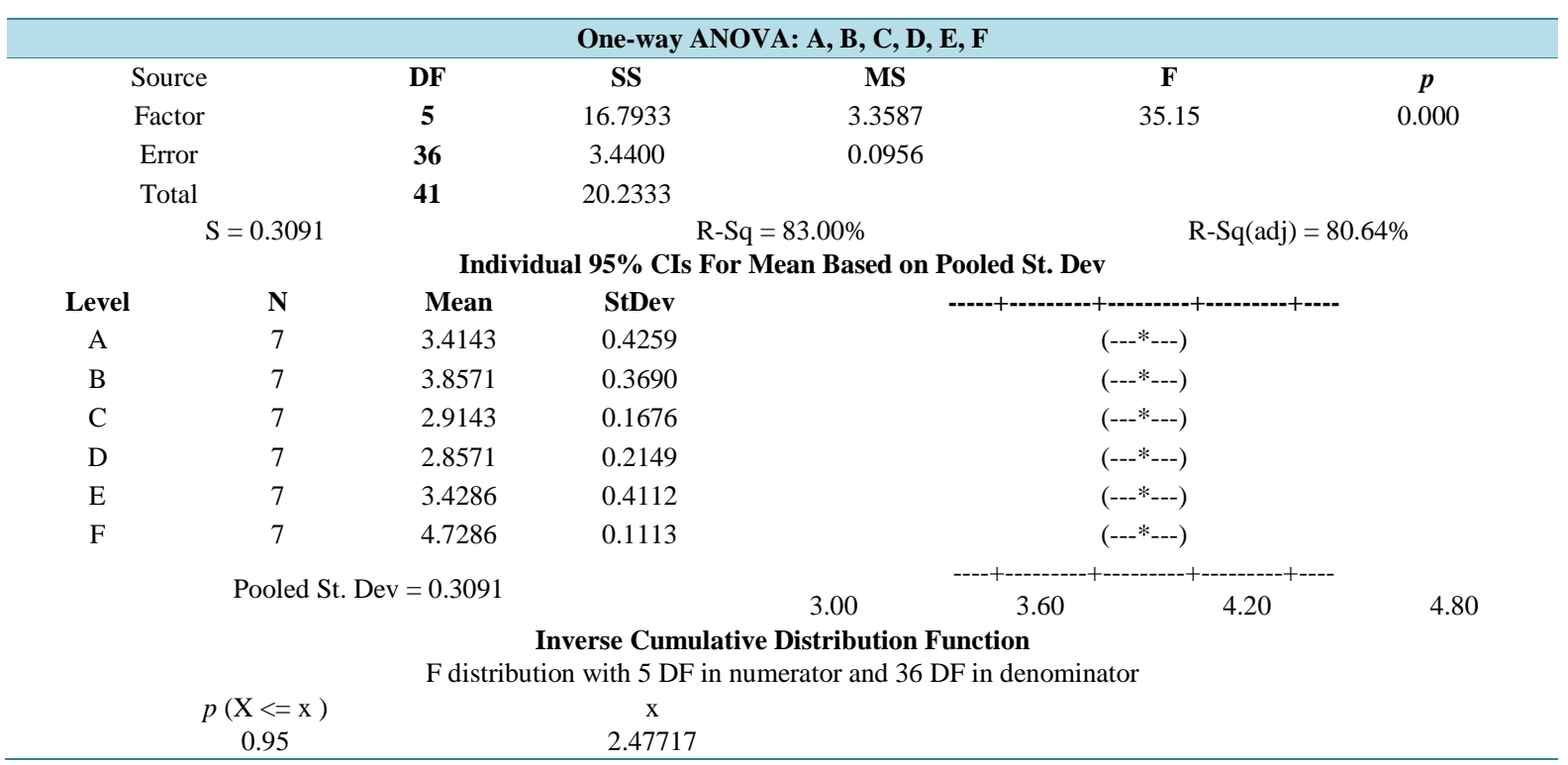

\section{Interpreting the results:}

$$
\begin{aligned}
& \alpha=0.05 \\
& f_{0}=35.15 \\
& f_{0.05,5.36}=2.48 \\
& f_{0}>f_{\alpha, 5.36}
\end{aligned}
$$

So $\mathbf{H}_{\mathbf{0} 3}$ is rejected. Also $p$-value $=0.0<\alpha=0.05$. There is significance difference in Safety of Lifeline Facilities level among the hospitals so far their effect on hospital disaster preparedness is concerned.

\subsection{Is There Any Significant Difference in Hospital Location and Areas Level among the Hospitals?}

$\mathbf{H}_{\mathbf{0} 4}$ : No significance difference in Hospital location and areas level among the hospitals.

$\mathbf{H 1}_{4}$ : There is significance difference in Hospital location and areas level among the hospitals.

\section{Minitab results of $\mathrm{H1}_{4}$}

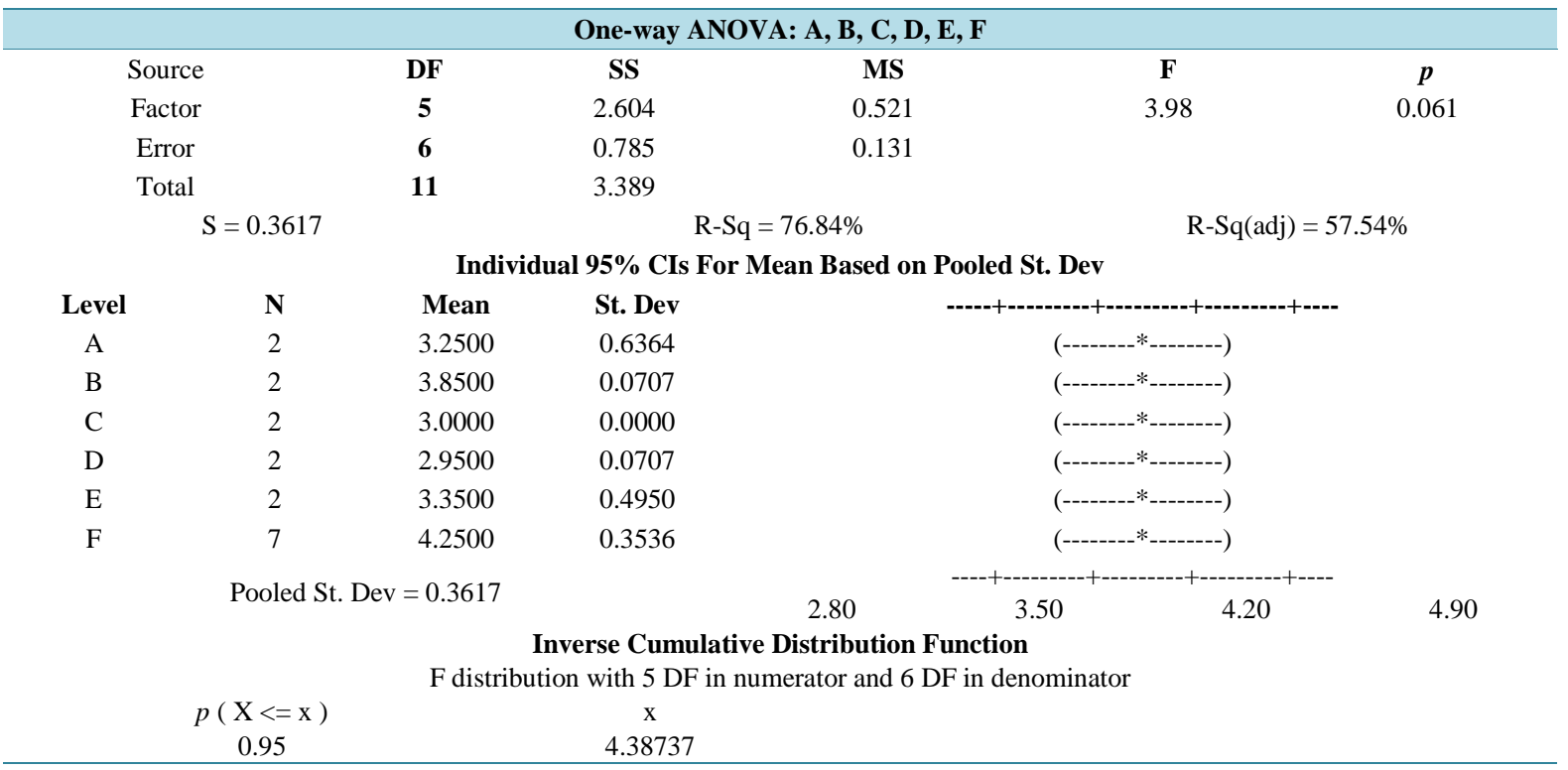


Interpreting the results:

$$
\begin{aligned}
& \alpha=0.05 \\
& f_{0}=3.98 \\
& f_{0.05,5.6}=4.39 \\
& f_{0}<f_{\alpha, 5.6}
\end{aligned}
$$

So fail to reject $\mathbf{H}_{\mathbf{0 4}}$. Also $p$-value $=0.061>\alpha=0.05$. There is not enough evidence to conclude that no significance difference in Hospital location and areas level among the hospitals at $\alpha=0.05$. More data and investigation must be done.

\subsection{Is There Any Significant Difference in Maintenance of Utilities Level among the Hospitals?}

$\mathbf{H}_{\mathbf{0} 5}$ : No significance difference in Maintenance of Utilities level among the hospitals.

$\mathbf{H 1}_{5}$ : There is significance difference in Maintenance of Utilities level among the hospitals.

Minitab results of $\mathrm{H1}_{5}$ :

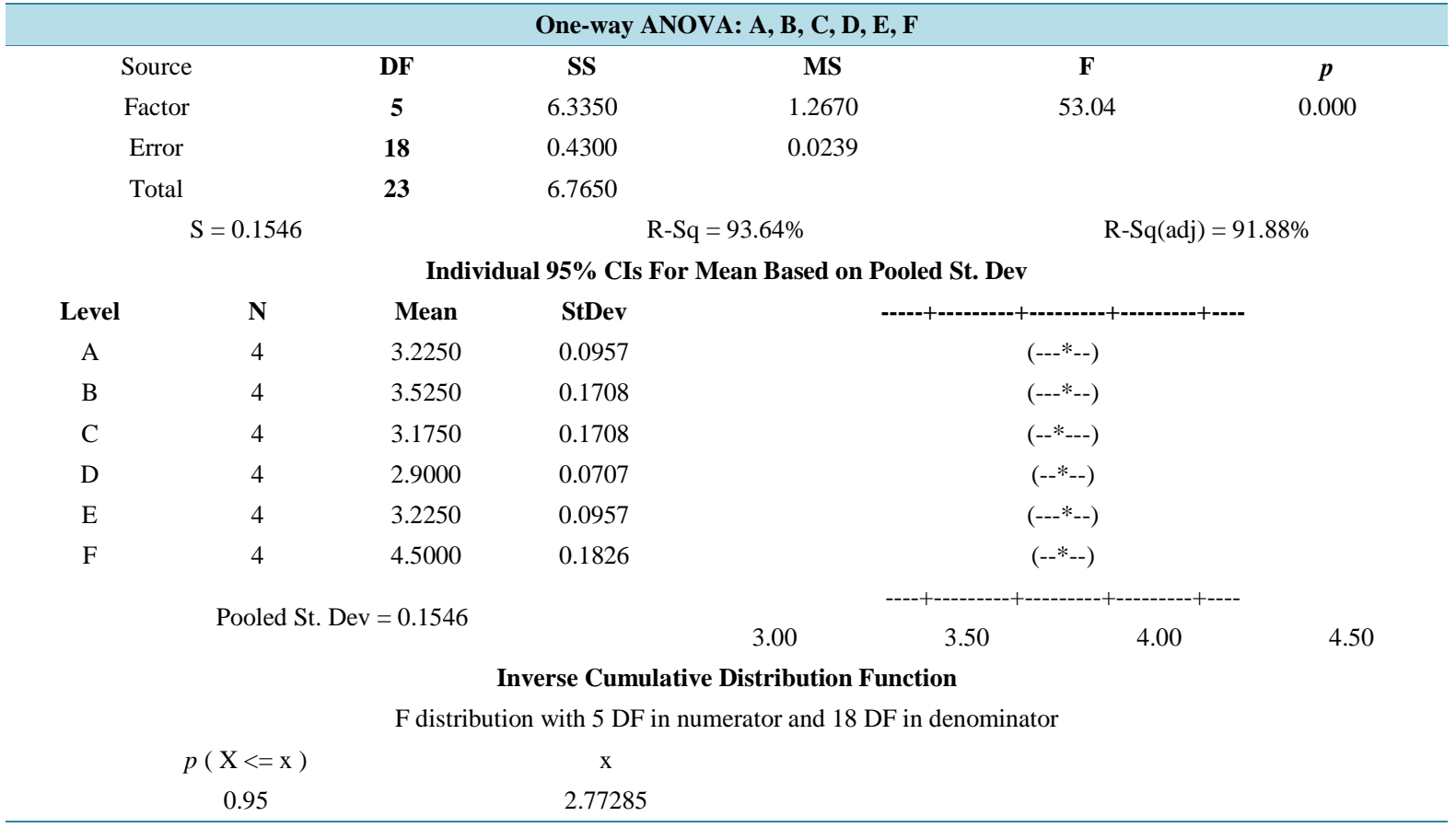

\section{Interpreting the results:}

$$
\begin{aligned}
& \alpha=0.05 \\
& f_{0}=53.04 \\
& f_{0.05,5.18}=2.77 \\
& f_{0}>f_{\alpha, 5.18}
\end{aligned}
$$

So $\mathbf{H}_{\mathbf{0} 5}$ is rejected. Also $p$-value $=0.0<\alpha=0.05$. There is significance difference in Maintenance of Utilities level among the hospitals so far their effect on hospital disaster preparedness is concerned.

\subsection{Is There Any Significant Difference in Surge Capacity Level among the Hospitals?}

$\mathbf{H}_{\mathbf{0} 6}$ : No significance difference in Surge capacity level among the hospitals.

$\mathbf{H 1}_{6}$ : There is significance difference in Surge capacity level among the hospitals.

Minitab results of $\mathrm{H1}_{6}$ : 


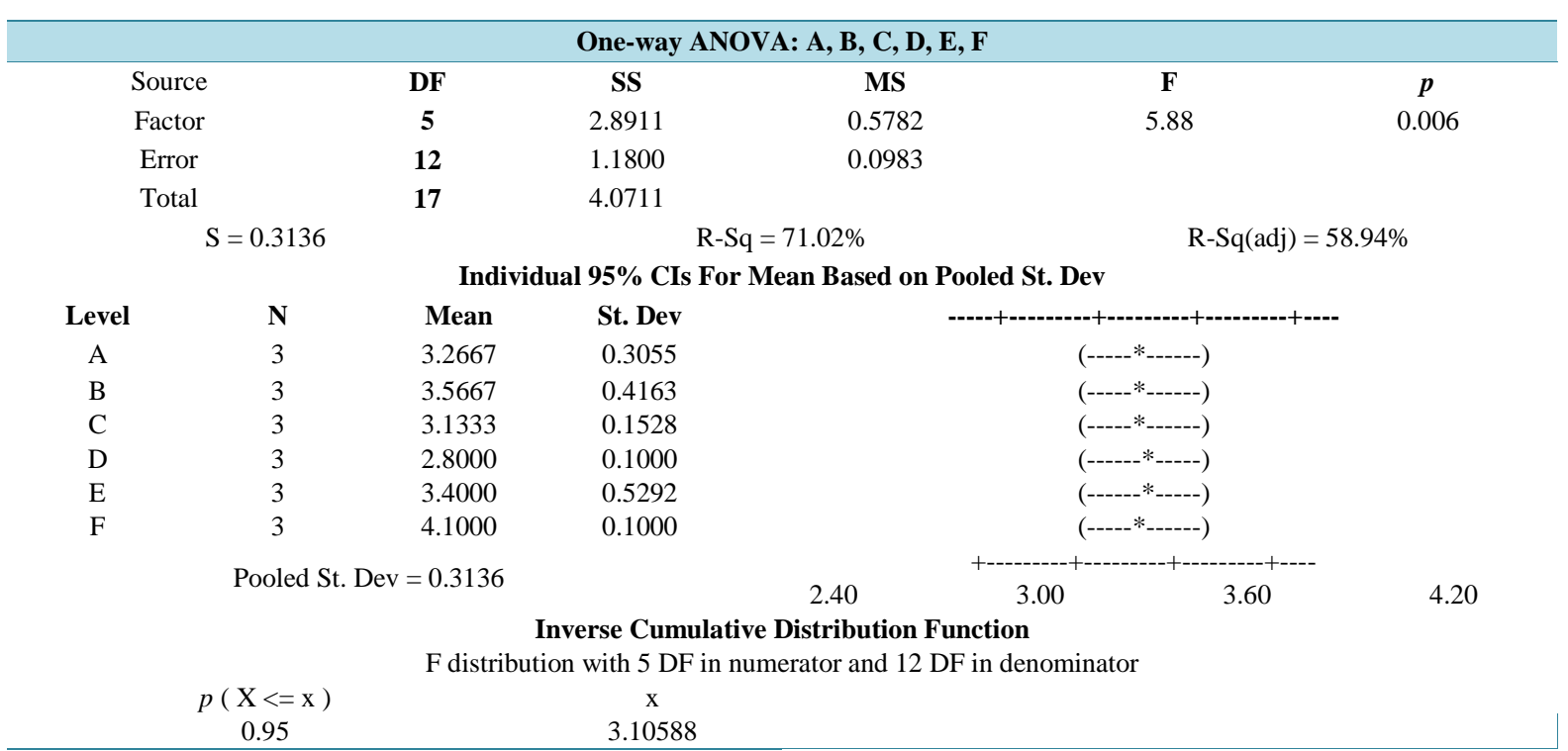

\section{Interpreting the results:}

$$
\begin{aligned}
& \alpha=0.05 \\
& f_{0}=5.88 \\
& f_{0.05,5.12}=3.11 \\
& f_{0}>f_{\alpha, 5.12}
\end{aligned}
$$

So $\mathbf{H}_{\mathbf{0 6}}$ is rejected. Also $p$-value $=0.006<\alpha=0.05$. There is significance difference in Surge capacity level among the hospitals so far their effect on hospital disaster preparedness is concerned.

\subsection{Is There Any Significant Difference in Emergency and Disaster Plan Level among the Hospitals?}

$\mathbf{H}_{\mathbf{0} 7}$ : No significance difference in Emergency and Disaster plan level among the hospitals.

H1 $_{7}$ : There is significance difference in Emergency and Disaster plan level among the hospitals.

\section{Minitab results of $\mathrm{H1}_{7}$ :}

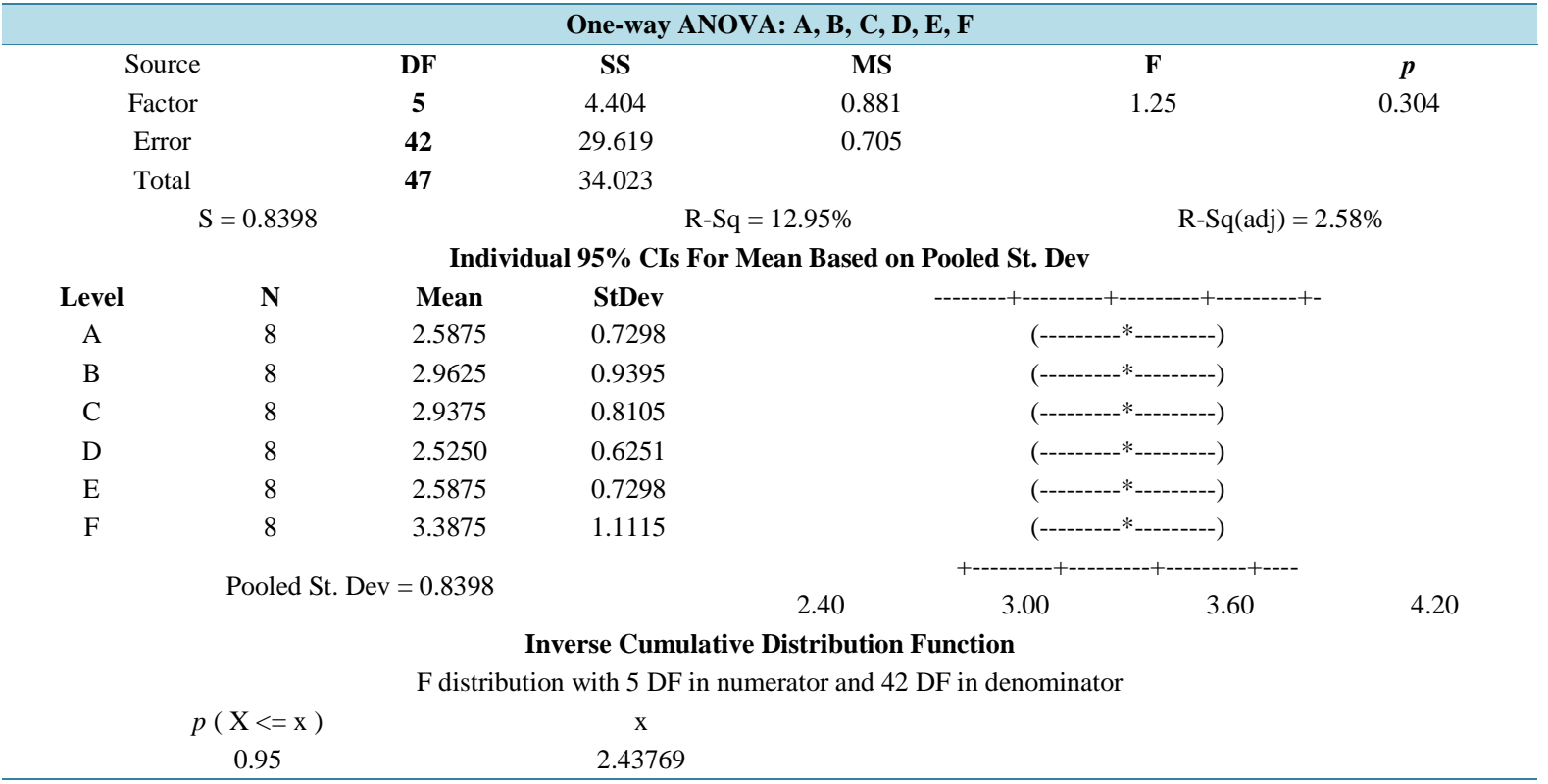


Interpreting the results:

$$
\begin{aligned}
& \alpha=0.05 \\
& f_{0}=1.25 \\
& f_{0.05,5.42}=2.44 \\
& f_{0}<f_{\alpha, 5.42}
\end{aligned}
$$

So fail to reject $\mathrm{H}_{\mathbf{0 7}}$. Also $p$-value $=0.304>\alpha=0.05$. There is not enough evidence to conclude that no significance difference in Emergency and Disaster plan level among the hospitals at $\alpha=0.05$. In all hospitals the Emergency and Disaster plan has lowest scores with weakness in education and training.

\subsection{Is There Any Significant Difference in Control of Communication and Coordination Level among the Hospitals?}

$\mathbf{H}_{\mathbf{0} 8}$ : No significance difference in Control of communication and coordination level among the hospitals. $\mathbf{H 1}_{\mathbf{8}}$ : There is significance difference in Control of communication and coordination level among the hospitals.

\section{Minitab results of $\mathrm{H1}_{\mathbf{8}}$ :}

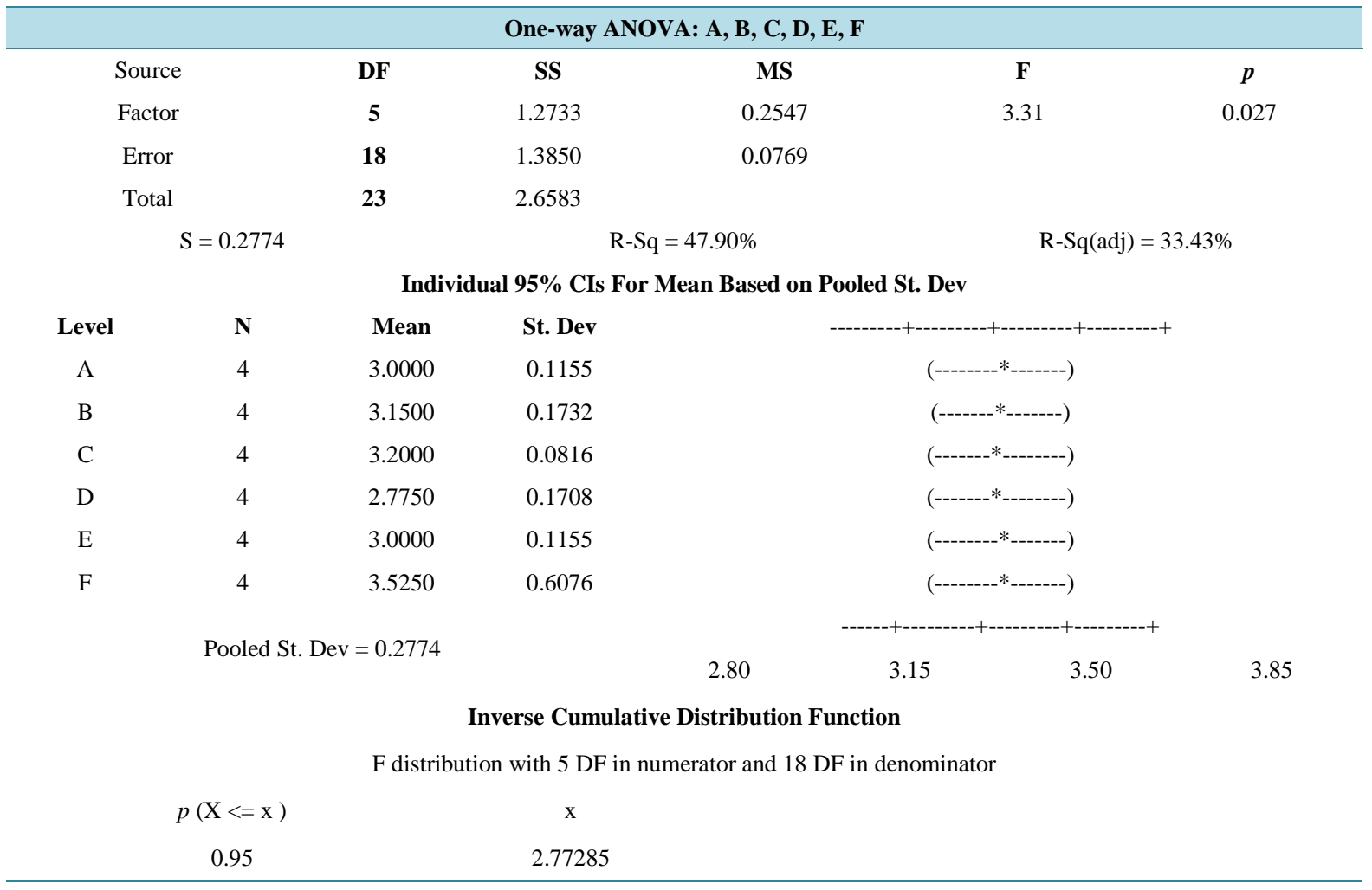

\section{Interpreting the results:}

So $\mathbf{H}_{\mathbf{0 8}}$ is rejected. Also $p$-value $=0.027<\alpha=0.05$. There is significance difference in Control of communication and coordination level among the hospitals so far their effect on hospital disaster preparedness is concerned.

Interpretation of all results:

For each hospital disaster preparedness indicators under this study, the score average for all received responses is calculated, consequently preparedness level in each hospital disaster preparedness indicators is evaluated, and results are interpreted as explained in Table 3.

Questionnaire summary of the average results for all the visited hospitals are shown in Table 4.

For example; consider the first part in hospital location and areas: "Site and Accessibility". Questions score 
Table 3. Results of interpretation key.

\begin{tabular}{cccccc}
\hline Preparedness $\% \boldsymbol{p}$ & $\boldsymbol{p} \leq \mathbf{2 0} \%$ & $\mathbf{2 0}<\boldsymbol{p} \leq \mathbf{4 0} \%$ & $\mathbf{4 0}<\boldsymbol{p} \leq \mathbf{6 0} \%$ & $\mathbf{6 0}<\boldsymbol{p} \leq \mathbf{8 0} \%$ & $\mathbf{8 0}<\boldsymbol{p} \leq \mathbf{1 0 0 \%}$ \\
\hline $\begin{array}{c}\text { Interpretation of } \\
\text { preparedness level }\end{array}$ & Poor & Fair & Good & Very Good & Excellent \\
\hline
\end{tabular}

Table 4. Questionnaire summary of hospitals results.

\begin{tabular}{|c|c|c|c|c|c|c|c|c|}
\hline No. & Hospital disaster $F$ & preparedness indicators & A & B & C & $\mathbf{D}$ & $\mathbf{E}$ & $\mathbf{F}$ \\
\hline 1 & Structure & 1.1 Hospital structure & 3.1 & 3.6 & 2.7 & 2.9 & 3.2 & 4.8 \\
\hline \multirow{7}{*}{2} & \multirow{7}{*}{$\begin{array}{l}\text { Architectural } \\
\text { and furnishings }\end{array}$} & 2.1 Safety of the roofing and ceilings & 3.2 & 3.5 & 2.8 & 2.6 & 3.3 & 4.9 \\
\hline & & 2.2 Safety of doors and windows & 3.0 & 3.2 & 2.9 & 2.7 & 3.1 & 4.8 \\
\hline & & 2.3 Safety of walls, divisions, partitions & 3.3 & 3.2 & 2.7 & 2.5 & 3.2 & 4.7 \\
\hline & & 2.4 Safety of floor coverings & 3.0 & 3.3 & 2.8 & 2.4 & 3.1 & 4.8 \\
\hline & & 3.1 Electrical tools System & 4.1 & 4.4 & 3.0 & 2.9 & 4.1 & 4.6 \\
\hline & & 3.2 Communication tools System & 3.2 & 4.0 & 2.7 & 3.0 & 3.2 & 4.7 \\
\hline & & 3.3 Water Supply tools System & 3.2 & 4.1 & 3.2 & 3.0 & 3.2 & 4.6 \\
\hline \multirow[t]{4}{*}{3} & \multirow{4}{*}{$\begin{array}{l}\text { Safety of Lifeline } \\
\text { Facilities }\end{array}$} & 3.4 Medical Gas tools System & 3.0 & 3.5 & 2.8 & 2.9 & 3.0 & 4.7 \\
\hline & & 3.5 Fire Suppression tools System & 3.8 & 3.9 & 3.0 & 2.8 & 3.8 & 4.8 \\
\hline & & 3.6 Emergency Exit System & 3.6 & 3.8 & 2.9 & 3.0 & 3.6 & 4.9 \\
\hline & & $\begin{array}{l}\text { 3.7 Heating, Ventilation and Air conditioning Systems in } \\
\text { Critical Areas }\end{array}$ & 3.1 & 3.7 & 3.0 & 3.0 & 3.1 & 4.7 \\
\hline \multirow{3}{*}{4} & \multirow{3}{*}{$\begin{array}{l}\text { Hospital location } \\
\text { and areas }\end{array}$} & 4.1 Site and Accessibility & 3.7 & 3.9 & 3.0 & 3.0 & 3.7 & 4.0 \\
\hline & & 4.2 Zoning of hospital units & 2.8 & 3.8 & 3.0 & 2.9 & 3.0 & 4.5 \\
\hline & & 5.1 Water supply system & 3.3 & 3.6 & 3.1 & 3.0 & 3.3 & 4.3 \\
\hline \multirow{4}{*}{5} & \multirow{4}{*}{$\begin{array}{l}\text { Maintenance of } \\
\text { Utilities }\end{array}$} & 5.2 Electrical system & 3.3 & 3.7 & 3.2 & 3.1 & 3.3 & 4.4 \\
\hline & & 5.3 Medical Gases Distribution System & 3.1 & 3.3 & 3.4 & 2.8 & 3.1 & 4.7 \\
\hline & & 5.4 Waste management system (solid and water) & 3.2 & 3.5 & 3.0 & 2.7 & 3.2 & 4.6 \\
\hline & & 6.1 Staff & 3.0 & 3.1 & 3.0 & 2.9 & 3.0 & 4.0 \\
\hline \multirow[t]{5}{*}{6} & \multirow[t]{5}{*}{ Surge capacity } & 6.2 Stuff & 3.6 & 3.9 & 3.1 & 2.8 & 4.0 & 4.1 \\
\hline & & 6.3 Structure & 3.2 & 3.7 & 3.3 & 2.7 & 3.2 & 4.2 \\
\hline & & 7.1 Hazard map & 1.0 & 1.0 & 1.0 & 1.0 & 1.0 & 1.0 \\
\hline & & 7.2 Information & 3.0 & 3.3 & 2.9 & 2.6 & 3.0 & 4.0 \\
\hline & & 7.3 Committee & 3.0 & 3.2 & 3.1 & 2.8 & 3.0 & 4.4 \\
\hline \multirow{6}{*}{7} & \multirow{6}{*}{$\begin{array}{l}\text { Emergency and } \\
\text { Disaster plan }\end{array}$} & 7.4 Preparedness & 2.7 & 3.1 & 3.0 & 2.6 & 2.7 & 3.8 \\
\hline & & 7.5 The Hospital Emergency Incident Command System & 2.0 & 2.2 & 3.2 & 2.8 & 2.0 & 2.8 \\
\hline & & 7.6 Stage of activation & 3.0 & 3.5 & 3.5 & 2.9 & 3.0 & 4.1 \\
\hline & & 7.7 Emergency operations center & 3.0 & 3.4 & 3.4 & 2.8 & 3.0 & 4.0 \\
\hline & & 7.8 Surveillance system & 3.0 & 4.0 & 3.4 & 2.7 & 3.0 & 3.0 \\
\hline & & 8.1 Transportation and Communication & 3.1 & 3.3 & 3.3 & 3.0 & 3.1 & 4.0 \\
\hline \multirow{3}{*}{8} & \multirow{3}{*}{$\begin{array}{l}\text { Control of } \\
\text { communication } \\
\text { and coordination }\end{array}$} & 8.2 Cooperative arrangement with local emergency plan & 2.9 & 3.0 & 3.2 & 2.7 & 2.9 & 4.1 \\
\hline & & 8.3 Referral procedure & 2.9 & 3.0 & 3.1 & 2.8 & 2.9 & 3.0 \\
\hline & & 8.4 Health facility networking & 3.1 & 3.3 & 3.2 & 2.6 & 3.1 & 3.0 \\
\hline
\end{tabular}

average and practice score averages of responses are represented in Table 5. These results in table are after collecting data from questionnaire.

After interpreting the results of score vs. hospital, the higher score was for hospital F and it is from private hospitals, the higher score from the governmental sector was for hospital. While, the lower score was for hospital D from the governmental sector as in Figure 3. There is noticeable fluctuation between Good and Very 
Table 5. Site and accessibility questions and their averages.

\begin{tabular}{lc}
\hline Site and accessibility Questions & Question average score \\
\hline How far is the facility from the main town/city? & 3.7 \\
Is the facility separated from the main town/city by a bridge? (If the bridge were affected by flood, etc.) & 3.5 \\
How far is the hospital from the main street/highway? & 3.8 \\
How many roads lead to the hospital? & 3.8 \\
What are the conditions of the roads that lead to the hospital? & 3.8 \\
Is route accommodate at least two ambulances at the same time) and well-paved roads? & 3.8 \\
Indicator score average & $\mathbf{7 4 . 3 \%}$ \\
Interpretation of preparedness level &
\end{tabular}

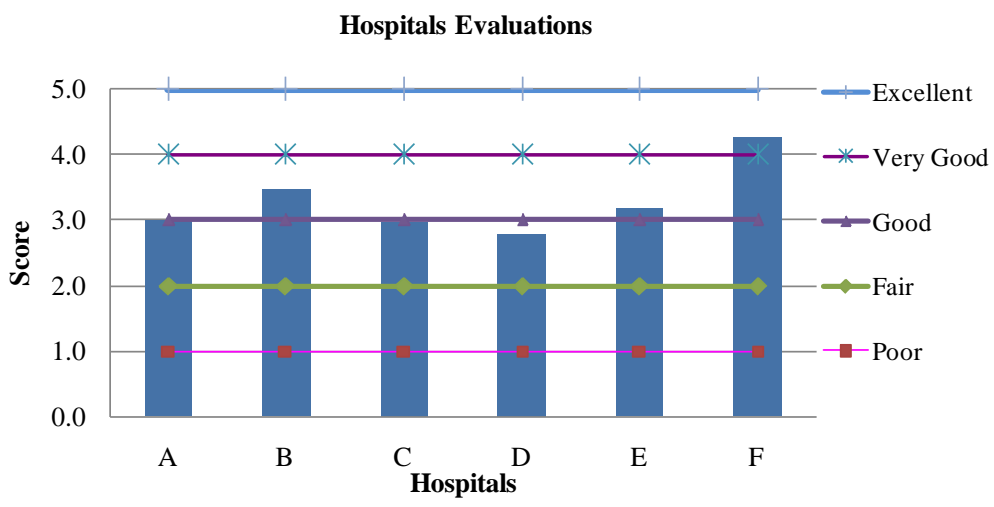

Figure 3. Score vs. hospital.

Good levels. All the hospitals in the analysis were concentrated and located almost in the Good level.

After interpreting the results for each Hospital vs. its indicators. The higher scores were for structure and architectural and furnishings $=4.8$ which were achieved in hospital $\mathrm{F}$ as in Table 6 .

Comparison with each hospital indicators are shown in Figure 4. Hospital F and hospital B have achieved the higher scores. The lowest rank is for Emergency and disaster plan (Figure 5). This field has the following sub indicators: Hazard map, Information, Committee, Preparedness, The Hospital Emergency Incident Command System, and Stage of activation, Emergency operations center and Surveillance system. The minimum scores were for hazard map and The Hospital Emergency Incident Command System.

\section{Hypotheses and Statistical Analysis}

For more detailed statistical analysis collected data were then entered into a spread sheet and then they were uploaded to the Statistical Program version 14, (MINITAB ${ }^{\circledR}$, 2004). Independent Groups F-Test and T-Test analyses were conducted [35]. F-test is used to determine whether the factor means are equal or not. Larger values of $\mathrm{F}$ support rejecting the null hypothesis that the means are equal.

The $p$-value used in hypotheses tests to help in deciding whether to reject or fail to reject a null hypothesis. The $p$-value is the probability of obtaining a test statistic that is at least as extreme as the actual calculated value, if the null hypothesis is true. That is, the $p$-value represents the probability of making a Type I error, or rejecting the null hypothesis when it is actually true.

The smaller the $p$-value, the smaller the probability is that you would be making a mistake by rejecting the null hypothesis. A commonly used cut-off value for the $p$-value is 0.05 . For example, if the calculated $p$-value of a test statistic is less than 0.05 , you reject the null hypothesis. The results are shown in Table 7 for each hypothesis tests.

\section{Conclusion}

This research was motivated by the need to find out the HDP in Jeddah, Saudi Arabia. The finding shows that 
Table 6. Each hospital vs. its’ indicators.

\begin{tabular}{ccccccccccc}
\hline Hospital & Structure & $\begin{array}{c}\text { Architectural } \\
\text { and } \\
\text { furnishings }\end{array}$ & $\begin{array}{c}\text { Safety of } \\
\text { Lifeline } \\
\text { Facilities }\end{array}$ & $\begin{array}{c}\text { Hospital } \\
\text { location } \\
\text { and areas }\end{array}$ & $\begin{array}{c}\text { Maintenance } \\
\text { of Utilities }\end{array}$ & $\begin{array}{c}\text { Surge } \\
\text { capacity }\end{array}$ & $\begin{array}{c}\text { Emergency } \\
\text { and Disaster } \\
\text { plan }\end{array}$ & $\begin{array}{c}\text { Control of } \\
\text { communication } \\
\text { and coordination }\end{array}$ & Score & $\begin{array}{c}\text { Preparedness } \\
\text { level }\end{array}$ \\
\hline A & 3.1 & 3.1 & 3.3 & 3.4 & 3.2 & 3.3 & 2.6 & 3.0 & 3.0 & Good \\
B & 3.6 & 3.3 & 3.9 & 3.9 & 3.5 & 3.7 & 2.9 & 3.2 & 3.5 & Very Good \\
C & 2.7 & 2.8 & 2.9 & 3.0 & 3.2 & 3.1 & 2.9 & 3.2 & 3.0 & Good \\
D & 2.9 & 2.6 & 2.9 & 3.0 & 2.9 & 2.8 & 2.5 & 2.8 & 2.8 & Good \\
E & 3.2 & 3.2 & 3.4 & 3.4 & 3.2 & 3.4 & 2.6 & 3.0 & 3.2 & Very Good \\
F & 4.8 & 4.8 & 4.7 & 4.3 & 4.5 & 4.1 & 3.4 & 3.5 & 4.3 & Excellent \\
\hline
\end{tabular}

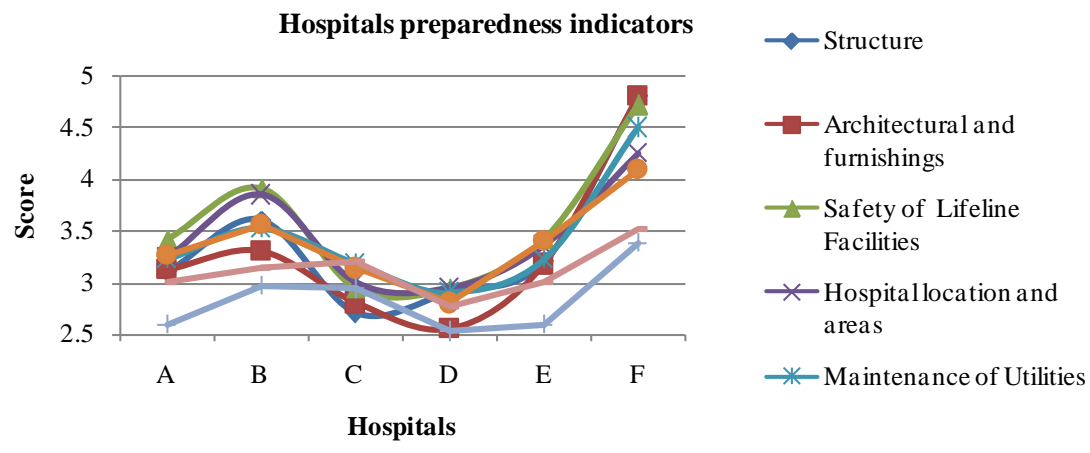

Figure 4. Score results vs. hospitals preparedness indicators.

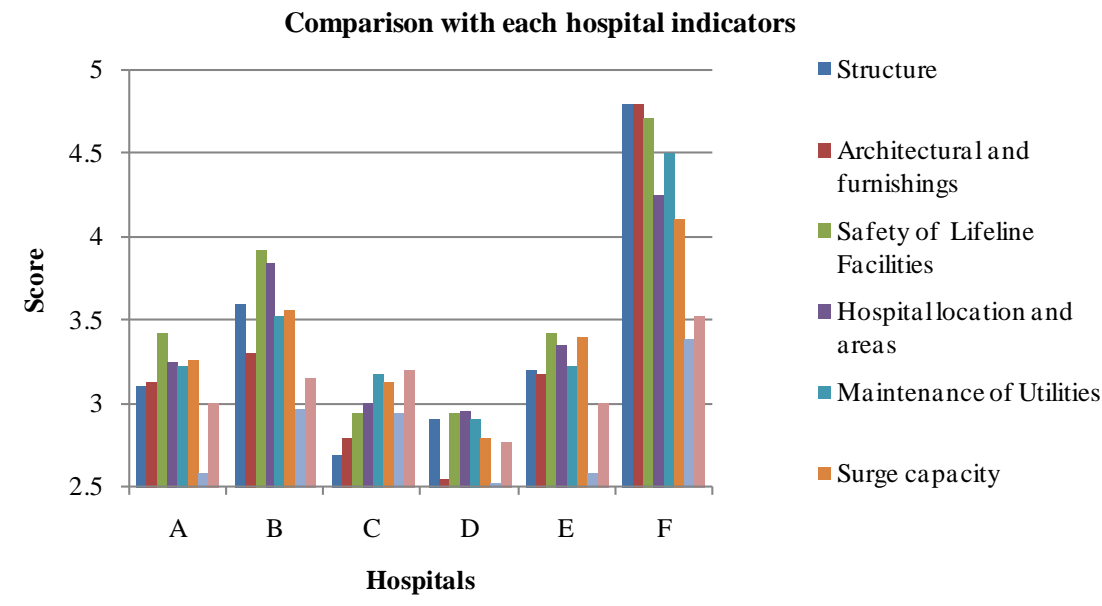

Figure 5. Comparison with each hospital indicators.

Table 7. Results for the hypothesis testing.

\begin{tabular}{cccc}
\hline Hypothesis & $\boldsymbol{p}$-value & F-value & Decision \\
\hline $\mathbf{H 1} \mathbf{1}_{\mathbf{1}}$ & 0.017 & 3.96 & Supported \\
$\mathbf{H 1}_{\mathbf{2}}$ & 0.000 & 2.77 & Supported \\
$\mathbf{H 1}_{\mathbf{3}}$ & 0.000 & 2.48 & Supported \\
$\mathbf{H 1}$ & 0.061 & 4.39 & Not Supported \\
$\mathbf{H 1}$ & 0.000 & 2.77 & Supported \\
$\mathbf{H 1}_{\mathbf{6}}$ & 0.006 & 3.11 & Supported \\
$\mathbf{H 1}$ & 0.304 & 2.44 & Not Supported \\
$\mathbf{H 1}$ & 0.027 & 2.77 & Supported \\
\hline
\end{tabular}


hospitals included in this study have tools and indicators in hospital preparedness but they lack both training and management during disaster. Weaknesses were apparent particularly in the following indicators: Emergency and Disaster plan; especially in Hazard map, Information, Committee, Preparedness, The Hospital Emergency Incident Command System, and Stage of activation, Emergency operations center and Surveillance system. Hospitals also have showed weakness in control of communication and coordination. Hospitals also have showed weakness in control of communication and coordination with its sub indicators (Transportation and Communication, Cooperative arrangement with local emergency plan, Referral procedure and Health facility networking). This research has provided hospital disaster preparedness (HDP) assessment tool that help in improving progress and effectiveness of hospital disaster preparedness improvement. Although the results of this study have provided new insights in recommendations, a continued research effort is still needed for greater hospitals disaster preparedness. The research shed light on HDP as being important in the preparedness in case of disasters. Therefore it is necessary for hospitals to understand that most of HDP is built in the hospital system itself.

\section{Limitations}

Results of this research were based on only one respondent from each hospital. Therefore, the respondent's feedback may not reflect accurately the hospital policy. Such personal bias may particularly affect in data collection with a lot of various practices and officialism (bureaucracy) procedures. Therefore the restriction of the data collection to a single city limits the generalization of the results.

\section{Recommendations}

Some recommendations can be taken into considerations to improve hospitals disaster preparedness such as education and training courses can be arranged for medical (undergraduate, postgraduate) and paramedical teams, volunteers. Local communities must also be made familiar with the hazards to which they are exposed and assist in building the local capacity for interpreting early warning and taking appropriate action to increase the safety of persons and ensuring the availability of essential resources. Each hospital can make their disaster hazard map and prepare at least for 3 - 5 hazards which they are vulnerable to for both external and internal hazards. Also a networking system can be established between all hospitals for human resource, emergency disaster equipment's and ancillary services including portable radiology, bloods lab and bank, training in disaster drill and sharing the experience. Also special budget for disaster and emergency equipment's should also be determined. As for primary care center it should share or integrate in local disaster response plan by treating mild cases so it well reduce the overload on big hospitals and help in stabilizing immediate and delayed cases before transferring them to hospitals if they came to primary health care center accidently, so the team should receive course in education training before drill.

\section{Acknowledgements}

This work is extracted from a research entitled "Hospital disaster preparedness in Jeddah—Saudi Arabia" which has been successfully approved by the Scientific Endowment for support of researches in King Abdulaziz University (Scientific Waqf) in Jeddah-Saudi Arabia at July 2011. It was prepared by Dr. Nidaa Abdullah Bajow and Eng. Shahnaz Mohammad Alkhalil, to whom this work primarily belongs.

\section{References}

[1] International Strategy for Disaster Reduction and World Health Organization (WHO) (2009) 2008-2009 World Disaster Reduction Campaign. Hospitals Safe from Disasters, Reduce Risk, Protect Health Facilities, Save Lives.

[2] Richter, P. (2008) Hospital Disaster Preparedness: Meeting a Requirement or Preparing for the Worst? An Update (Eleven Years after). American Society for Healthcare Engineering, Chicago.

[3] University Hospital Submergence. (2009) http://enayh.com/News/53-daily/239-34.html

[4] WHO and Western Pacific Region (2008) Hospitals Should Be Safe from Disasters Reduce Risk, Protect Health Facilities, Save Lives. Manual.

[5] World Health Organization (2011) Safe Hospitals in Emergencies and Disaster; Structural, Non-Structural and Functional Indicators. World Health Organization, Regional Office for Western Pacific.

[6] Centers for Disease Control and Prevention and American Water Works Association (2011) Emergency Water Supply 
Planning Guide for Hospitals and Health Care Facilities. U.S. Department of Health and Human Services, Atlanta.

[7] Rouse, J. and Reed, B. (2011) Technical Notes on Drinking-Water, Sanitation and Hygiene in Emergencies. Solid Waste Management in Emergencies. World Health Organization, Geneva.

[8] National Environmental Training Center for Small Communities (2002) Protecting Your Community’s Assets: A Guide for Small Wastewater Systems.

[9] Hammond, J. (2005) Mass Casualty Incidents: Planning Implications for Trauma. Scandinavian Journal of Surgery, 94, 267-271.

[10] National Association of Public Hospitals and Health Systems (2007) Research Brief. Hospital Staffing and Surge Capacity during a Disaster Event.

[11] Attachment Requirements and Expectations by Source Hospital Emergency Preparedness (2007) A Vision of Preparedness-Hospital Emergency Management. New Mexico Department of Health. Bureau of Health Emergency Management. Draft-Requirements by Goal and Source-Page 1, 25 July 2007.

[12] Felland, L., Katz, A., Liebhaber, A. and Cohen, G. (2008) Developing Health System Surge Capacity: Community Efforts in Jeopardy. Center for Studying Health System Change, Research Brief No. 5.

[13] Hick, J.L., Hanfling, D., Burstein, J.L., DeAtley, C., Barbisch, D., Bogdan, G.M. and Cantrill, S. (2004) Health Care Facility and Community Strategies for Patient Care Surge Capacity. The American College of Emergency Physicians. Annals of Emergency Medicine, 44, 253-261. http://dx.doi.org/10.1016/j.annemergmed.2004.04.011

[14] World Health Organization (WHO) (2006) Field Manual for Capacity Assessment of Health Facilities in Responding to Emergencies. WPRO Non Serial Publication. WHO Regional Office for the Western Pacific.

[15] Guidelines for Hospital Emergencies Preparedness Planning (2002-2008) Chapter 2: Some Important Considerations for Making Your Hospital Emergency Plan. GOI-UNDP Disaster Risk Management Programme, India.

[16] Hazard Vulnerability Analysis (2009) California Hospital Association. http://www.calhospitalprepare.org/node/170

[17] Boer, J. and Dubouloz, M. (2000) Handbook of Disaster Medicine: Emergency Medicine in Mass Casualty Situations. International Society of Disaster Medicine.

[18] KMA Managed Care Committee and the KMA Medical Manager Advisory Group (2000) KMA Model Disaster Plan for a Physician Practice.

[19] Gifford, A. and Gougelet, R. (2008) Fundamental Disaster Management. Chapter 2. Intensive Care Unit Microcosm within Disaster Medical Response. Society of Critical Care Medicine, USA. http://www.sccm.org/Fundamentals/FDM/Pages/default.aspx

[20] Pan American Health Organization (2008) Hospital Safety Index: Guide for Evaluators. Series Hospitals Safe from Disasters, 1, PAHO, Washington DC, 107 p.

[21] World Health Organization Regional Office for the Western Pacific (2010) Hospital and Health Facility Emergency Exercises-Guidance Materials.

[22] Bagaria, J., Heggie, C., Abrahams, J. and Murray, V. (2009) Evacuation and Sheltering of Hospitals in Emergencies: A Review of International Experience. Prehospital and Disaster Medicine, 24, 461-467.

[23] Zane, R.D. and Prestipino, A.L. (2004) Implementing the Hospital Emergency Incident Command System: An Integrated Delivery System’s Experience. Prehospital and Disaster Medicine, 19, 311-317.

[24] O’Neill, P.A. (2005) The ABC’s of Disaster Response. Scandinavian Journal of Surgery, 94, 259-266.

[25] Government of India and UNDP India Disaster Risk Management Program (2010) One Million Safe Schools and Hospitals Campaign, Guidance Notes, Emergency and Disaster Preparedness for Health Facilities.

[26] Hospital Preparedness for Biological Terrorist Attack. (2005) (Bioterrorism)/EMDM Material.

[27] Montgomery, D.C. and Runger, G.C. (2007) Applied Statistics and Probability for Engineers. 4th Edition, John Wiley \& Sons, Inc., Hoboken.

[28] Lazar, E.J., Cagliuso Sr., N.V. and Gebbie, K.M. (2009) Are We Ready and How Do We Know? The Urgent Need for Performance Metrics in Hospital Emergency Management. Disaster Medicine and Public Health Preparedness, 3, 5760. http://dx.doi.org/10.1097/DMP.0b013e31817e0e7f

[29] Higgins, W., Wainright, C., Liu, N. and Carrico, R. (2004) Assessing Hospital Preparedness Using an Instrument Based on the Mass Casualty Disaster Plan Checklist: Results of a Statewide Survey. American Journal of Infection Control, 32, 327-332. http://dx.doi.org/10.1016/j.ajic.2004.03.006

[30] Kaji, A.H. and Lewis, R.J. (2006) Hospital Disaster Preparedness in Los Angeles County. Academic Emergency Medicine, 13, 1198-1203. http://dx.doi.org/10.1111/j.1553-2712.2006.tb01648.x

[31] Kollek, D. and Cwinn, A.A. (2011) Hospital Emergency Readiness Overview Study. Prehospital and Disaster Medi- 
cine, 26, 159-165. http://dx.doi.org/10.1017/S1049023X11006212

[32] Crosse, M., Bogart, G., Cohen, J., et al. (2003) Hospital Preparedness: Most Urban Hospitals Have Emergency Plans but Lack Certain Capabilities for Bioterrorism Response. General Accounting Office, Washington, D.C., GAO-03-924.

[33] Leiba, A., Ashkenasi, I., Nakash, G., Pelts, R., Schwartz, D., Goldberg, A., Levi, Y. and Bar-Dayan, Y. (2006) Response of Thai Hospitals to the Tsunami Disaster. Prehospital and Disaster Medicine, 21, s32-s37.

[34] Top, M., Gider, O. and Tas, Y. (2010) An Investigation of Hospital Disaster Preparedness in Turkey. Journal of Homeland Security and Emergency Management, 7, Article 69. http://dx.doi.org/10.2202/1547-7355.1781

[35] Cavallo, E. and Noy, I. (2010) The Economics of Natural Disasters. http://www.iadb.org/res/publications/pubfiles/pubIDB-WP-124.pdf 
Scientific Research Publishing (SCIRP) is one of the largest Open Access journal publishers. It is currently publishing more than 200 open access, online, peer-reviewed journals covering a wide range of academic disciplines. SCIRP serves the worldwide academic communities and contributes to the progress and application of science with its publication.

Other selected journals from SCIRP are listed as below. Submit your manuscript to us via either submit@scirp.org or Online Submission Portal.
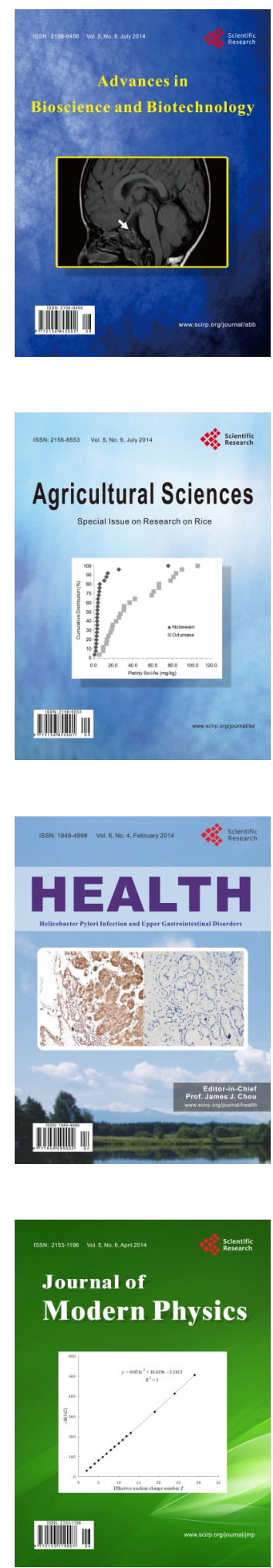
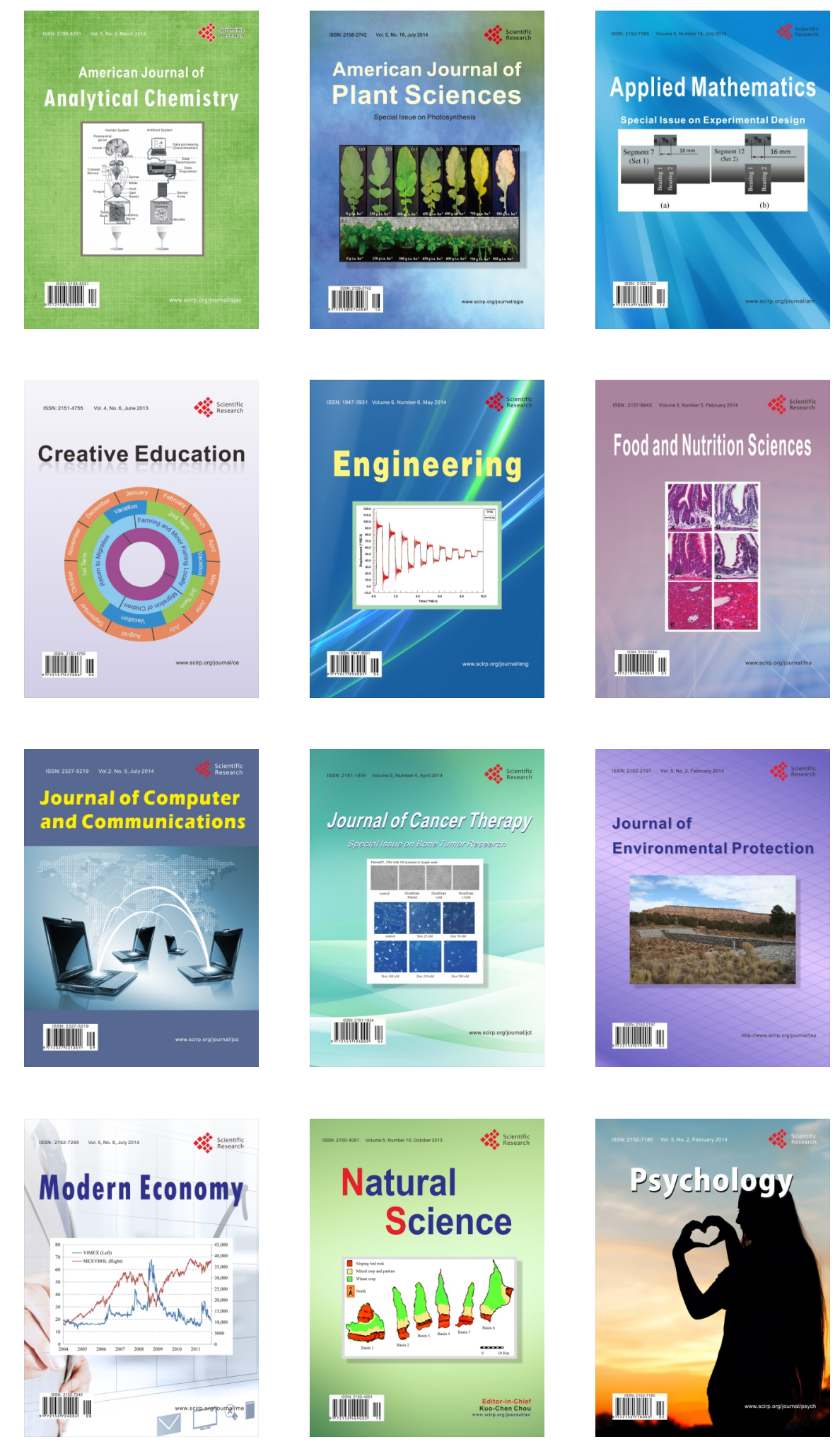